\title{
Application of synthetic bi-layer dermal matrix in severely burned child - a case study
}

\author{
Anna Zioła, Andrzej M. Bulandra, Tomasz Koszutski \\ Department of Paediatric Surgery and Urology, \\ Medical University of Silesia \\ ŚLĄSI UNIWERSYTET MEDYCZNY \\ W KATOWICACH \\ Uppersilesian Child Health Center, Katowice, Poland
}

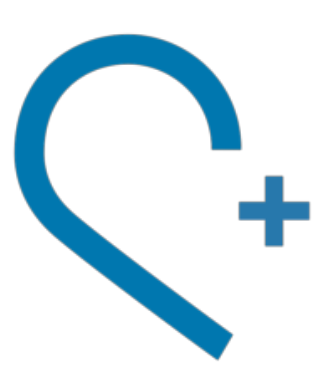

\section{INTRODUCTION}

Treatment of severely burned children is a serious clinical problem. The priority is to treat the burn disease and close the burn wound as soon as possible. The best treatment method is the early excision of necrosis and the coverage of burn wounds with autologous skin grafts. In cases of extensive burns, it can be difficult due to the deficit of the donor areas.

\section{CASE PRESENTATION}

A case of a 3-years old severely burned child is presented. As a result of ignition of the seat in which the boy was fastened in the car, he suffered extensive third and fourth degree burns of the dorsal surface of the body - at least $47 \%$ TBSA.

\section{SURGICAL TREATMENT}

The necrosis was deeply resected during the first 72 hours after injury. A half of the burned area was covered by the autologous skin grafts, but the deficit of donor areas caused the need to close the rest of wounds in a different manner. A be-layer synthetic dermal matrix was applied to temporarily close the wounds. Later, the matrix was the basis for autologous skin transplantation.

The procedure allowed to obtain the time needed for donor sites healing before subsequent skin donation. It also caused the restoration of the damaged layer of the dermis, which improved the functional and cosmetic effect of the treatment.

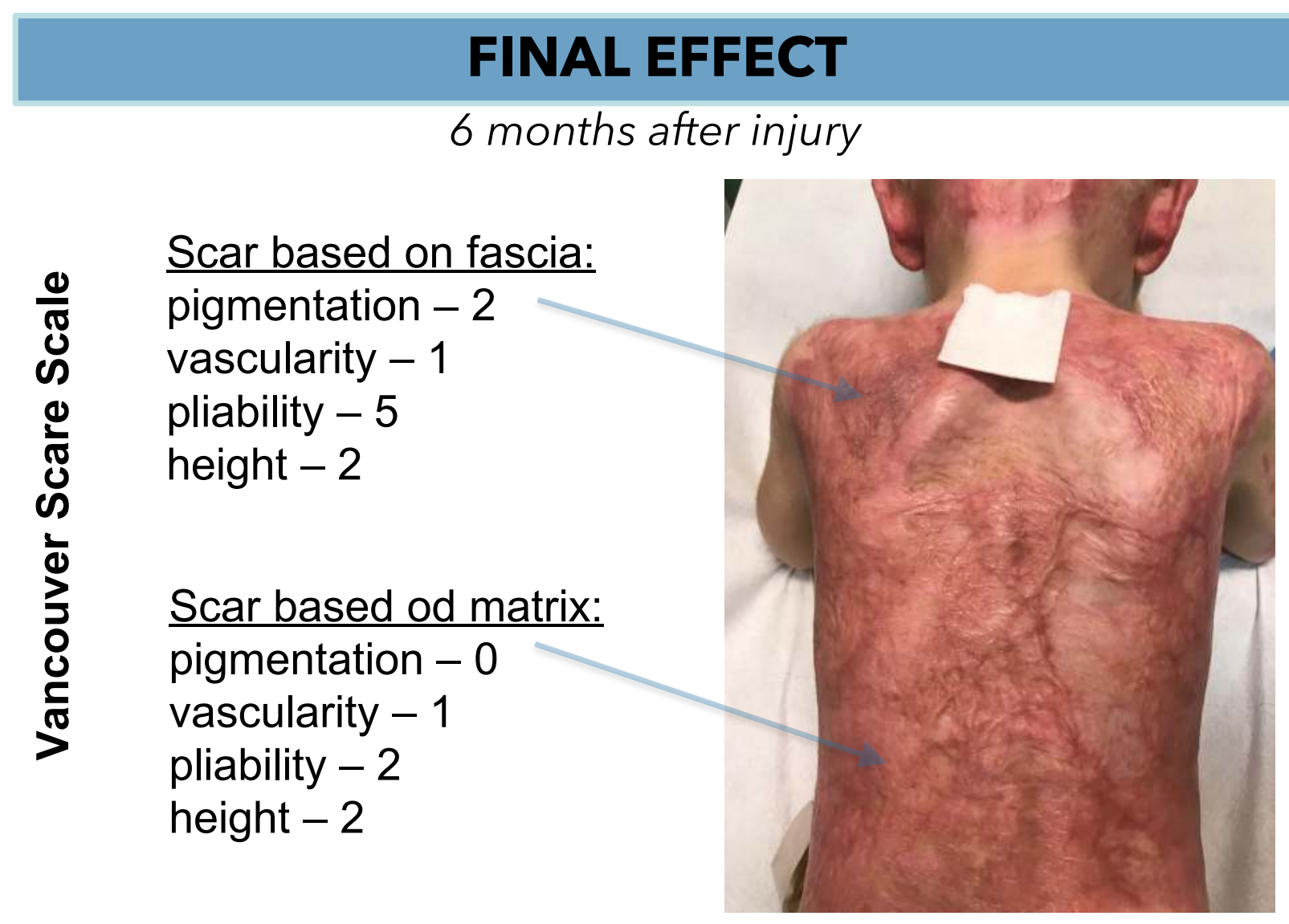

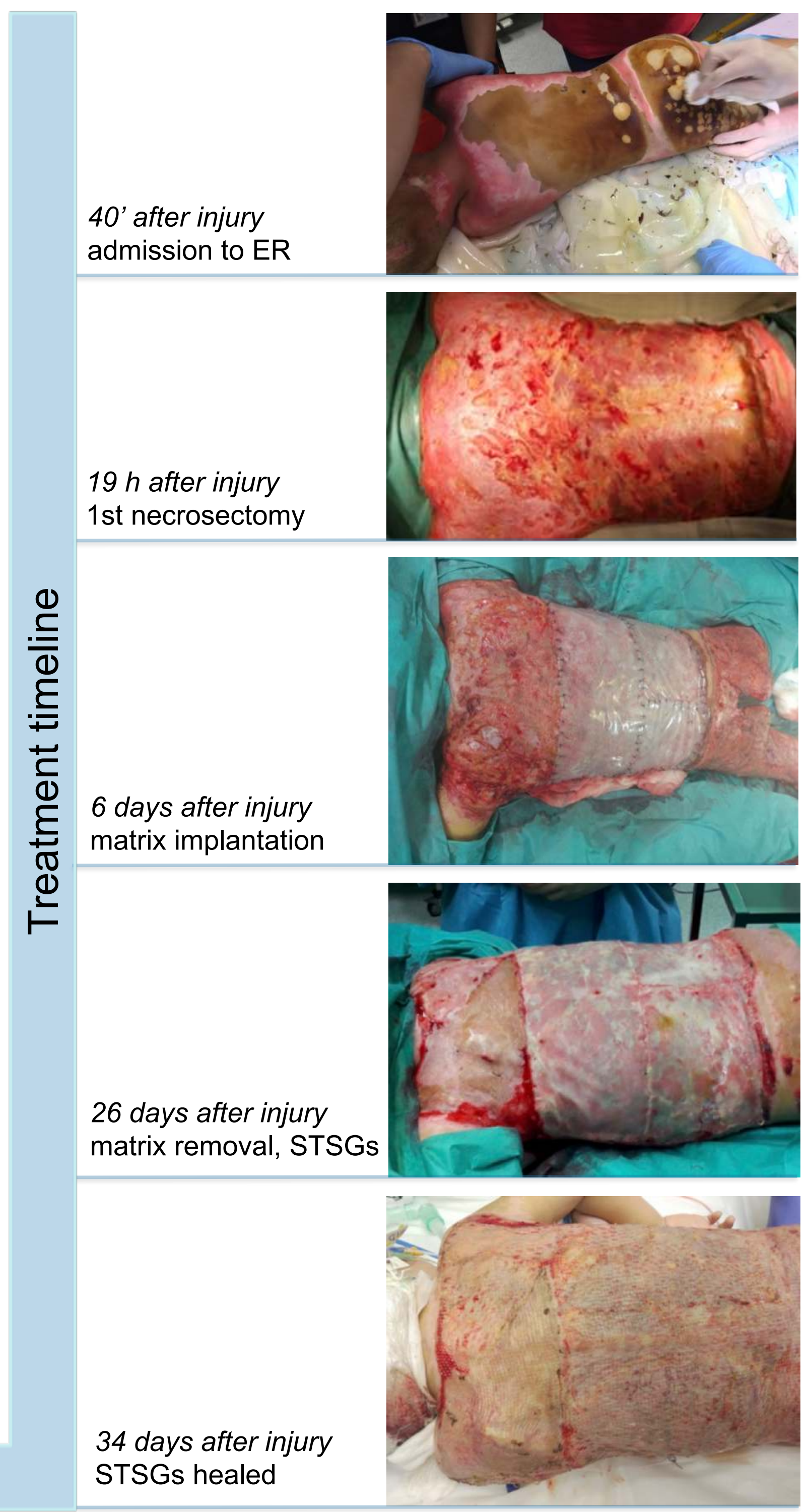

\section{Conclusion}

In presented case application of synthetic skin matrix gave a good final result. However, the best way to burn wound closure is primary autologous skin grafting, the matrix application should be considered in special circumstances like insufficient donor area. 